\title{
Amazonía 2009. Áreas protegidas y territorios indígenas
}

\section{Philippe Erikson}

\section{OpenEdition}

\section{Journals}

Édition électronique

URL : https://journals.openedition.org/jsa/11607

DOI : 10.4000/jsa. 11607

ISSN : $1957-7842$

\section{Éditeur}

Société des américanistes

\section{Édition imprimée}

Date de publication : 5 décembre 2010

Pagination : 319-320

ISSN : 0037-9174

\section{Référence électronique}

Philippe Erikson, «Amazonía 2009. Áreas protegidas y territorios indígenas », Journal de la Société des américanistes [En ligne], 96-2 | 2010, mis en ligne le 22 juillet 2010, consulté le 04 septembre 2022. URL : http://journals.openedition.org/jsa/11607 ; DOI : https://doi.org/10.4000/jsa. 11607

Ce document a été généré automatiquement le 4 septembre 2022.

Tous droits réservés 


\title{
Amazonía 2009. Áreas protegidas y territorios indígenas
}

\author{
Philippe Erikson
}

\section{RÉFÉRENCE}

Amazonía 2009. Áreas protegidas y territorios indígenas, Red Amazónica de Información Socioambiental Georreferenciada, 2009 [www.raisg.socioambiental.org/, consulté le 29/09/2010]

1 Bien qu'il ne s'agisse pas à proprement parler d'un ouvrage, il vaut indéniablement la peine de signaler aux américanistes cet impressionnant document publié par la RAISG (Red Amazónica de Información Socioambiental Georreferenciada, http:// www.raisg.socioambiental.org/) : rien moins qu'une carte de toutes les aires indigènes protégées d'Amazonie (lato sensu), tous pays confondus, produite en collaboration par les institutions de recherche, gouvernementales ou non gouvernementales, les plus représentatives de l'ensemble des pays du bassin amazonien et des Guyanes (à l'exception provisoire du Guyana et du Surinam).

Éminemment lisible, la carte permet de localiser rapidement les zones concernées (dont les noms coïncident souvent avec celui des populations qu'elles abritent) en rapport avec le réseau routier et fluvial, tout en fournissant des données sur le statut juridique des différentes aires naturelles ou territoires protégés.

Le recto de la carte fourmille de données d'ordre démographique, géopolitique, bioécologique, ou encore juridique, sous forme de textes (en version bilingue espagnol/ portugais) et de tableaux qui permettent de se faire une idée précise du poids relatif des populations indigènes et amazoniennes dans leurs pays respectifs. Un travail considérable, rendant compte d'une aire de 7,8 millions de $\mathrm{km}^{2}$, partagée par neuf Étatsnations, hébergeant 33 millions de personnes dont 370 peuples amérindiens (sans compter les groupes en isolement volontaire) représentant 1,6 million de personnes réparties sur plus de 200 territoires... 
4 Signalons pour conclure que la carte est disponible en ligne (y compris en version anglaise) à l'adresse citée en référence, qui précise également les points de vente de l'incontournable version papier de ce précieux outil de travail, document essentiel tant pour les ethnologues que pour les politologues, les géographes et les indigénistes.

\section{AUTEURS}

\section{PHILIPPE ERIKSON}

Université Paris Ouest Nanterre La Défense 